\title{
Evolução dos processos de aprendizagem e das competências tecnológicas das áreas de gestão de projeto, operações e manutenção do Metrô de São Paulo de 1968 a 2010
}

\author{
Development of learning processes and technological capabilities of \\ Metrô São Paulo in the areas of operations, project management, and \\ maintenance from 1968 to 2010
}

\author{
Ricardo Cesso da Silva ${ }^{1}$ \\ Eva Stal $^{2}$
}

\begin{abstract}
Resumo: O artigo examina os processos de aprendizagem na acumulação de competências tecnológicas no Metrô SP, desde sua fundação, em 1968, até 2010. Para tal, utilizou-se um modelo teórico (FIGUEIREDO, 2003) adaptado às especificidades da empresa em questão, que divide o aprendizado em etapas de capacitação perceptíveis e sequenciais. Houve duas fases distintas na história da empresa: entre 1968 e 1974, ocorreu o processo de transferência de tecnologia, com intensa aprendizagem, resultando na acumulação de competências rotineiras; entre 1975 e 2010 , seguiu-se a acumulação de competências inovadoras. Foi empregado o método do estudo de caso, que incluiu pesquisa bibliográfica e documental e entrevistas com quatro gestores. Os resultados mostram a adequação do modelo utilizado para a mensuração dos diferentes níveis de capacitação tecnológica.
\end{abstract}

Palavras-chave: Capacitação tecnológica. Aprendizagem tecnológica. Transferência de tecnologia.

\begin{abstract}
This study evaluates the learning processes involved in the accumulation of technological capabilities in Metrô SP from its foundation in 1968 up to 2010. A theoretical model adapted from Figueiredo (2003) to the company being studied, which divides the learning process into distinguishable and sequential capability stages, was used. There were two distinct phases in the history of the company: between 1968 and $1974-a$ technology transfer process with intensive learning took place resulting in the accumulation of routine skills; between 1975 and 2010 - the first stage was followed by the accumulation of innovative competencies. The case study method was used, which included bibliographical and documental research and interviews with four managers. The results show that the model used to measure the different levels of technological capability was quite appropriate.
\end{abstract}

Keywords: Technological capability. Technological learning. Technology transfer.

\section{Introdução}

O processo de industrialização em países em desenvolvimento ocorreu mais fortemente após a Segunda Guerra Mundial, sendo considerado como recente ou tardio, em comparação aos países centrais. As mudanças tecnológicas, em seu estágio inicial, são copiadas e adaptadas de soluções desenvolvidas nos países desenvolvidos, que constituem a principal fonte de acesso a novas tecnologias. Mas é preciso haver uma competência tecnológica prévia para que ocorra, de fato, a transferência desse conhecimento. Para Lall (1992), essa competência se traduz em investimentos, capital humano e esforço tecnológico, e passa, necessariamente, por três estágios - competências rotineiras, intermediárias e avançadas (inovadoras), sendo a última responsável pela geração de conhecimento totalmente novo.

O conceito de competências tecnológicas abrange os recursos existentes sob a forma de conhecimento, experiências individuais e sistemas organizacionais, que são necessários para criar e gerenciar mudanças tecnológicas (BELL; PAVITT, 1995). No contexto econômico atual, a acumulação dessas competências é condição fundamental para o aprimoramento do desempenho técnico e econômico em empresas e países, influenciando diretamente a sua competitividade internacional (FIGUEIREDO, 2003).

Outro aspecto importante refere-se à verificação e mensuração da aprendizagem e das competências

\footnotetext{
${ }^{1}$ Departamento de Ciências Gerenciais Universidade Nove de Julho - UNINOVE, CEP 05001-100, São Paulo, SP, Brasil

${ }^{2}$ Faculdades Metropolitanas Unidas - FMU, Av. Liberdade, 899, Liberdade, CEP 01503-001, São Paulo, SP, Brasil,

e-mail: eva.stal@terra.com.br
}

Recebido em 23/4/2012 — Aceito em 1/2/2013

Suporte financeiro: Nenhum. 
tecnológicas. As estatísticas de patentes têm sido tradicionalmente utilizadas para medir o resultado da pesquisa tecnológica, mas seu uso como indicador de inovação ainda é objeto de debate. As patentes medem o conhecimento codificado, enquanto uma grande parte das competências específicas das empresas reside no conhecimento tácito. Entretanto, é mais difícil medir a competência tecnológica com base nesse conhecimento.

Assim, a construção dessas competências é influenciada pelo processo de aprendizagem tecnológica (KIM, 2005; FIGUEIREDO, 2003), que contempla a aquisição ou desenvolvimento de conhecimentos nas empresas, bem como sua extensão do âmbito individual para o organizacional, possibilitando a construção e acumulação de competências necessárias ao desenvolvimento de inovações.

O processo de industrialização dos países em desenvolvimento foi marcado por forte dependência tecnológica dos países centrais. Estes países partiram de uma condição inicial de baixa competitividade no mercado mundial e, para atingir uma condição de maturidade industrial, foi necessária a acumulação de competências tecnológicas, o que, por sua vez, exigiu o emprego de esforços por parte de empresas e governos. Assim, sua estratégia de transferência de tecnologia foi marcada por medidas protecionistas e políticas de substituição de importações, objetivando construir competências tecnológicas com base em processos de aprendizagem. O período de substituição de importações perdurou até o final dos anos 80, quando se intensificou o processo de globalização e a liberalização comercial, aumentando ainda mais o patamar de competitividade internacional e, consequentemente, a importância do processo de acumulação de competências tecnológicas (FIGUEIREDO, 2005).

Até a década de 1960, poucos estudos abordavam os avanços tecnológicos naqueles países, pois se aceitava que eles ocorriam apenas em economias industrializadas (LALL, 1992). A transferência de tecnologia para países emergentes possuía, em geral, um caráter passivo, baseado na simples adoção de tecnologias provenientes dos países desenvolvidos. No entanto, para que a absorção das inovações resulte na construção e acumulação de competências tecnológicas, ela exige um papel ativo por parte dos países, para adaptá-las às condições locais e, a partir daí, aprimorá-las e difundi-las (BELL; PAVITT, 1995). Os países emergentes utilizam diversas fontes para acessar novas tecnologias e viabilizar a aprendizagem tecnológica, como licenciamento, investimento estrangeiro direto, joint ventures, subcontratação, treinamento de mão de obra no exterior e aquisições de empresas.
No entanto, diferentes níveis de desenvolvimento tecnológico entre os países resultam de diferenças em seus esforços internos, devido a políticas distintas de absorção e difusão das tecnologias importadas nas economias locais. A Coreia do Sul buscou o desenvolvimento tecnológico por meio de baixa dependência de investimentos estrangeiros, medidas protecionistas e fortemente seletivas em relação à entrada desse capital, foco no crescimento de grandes empresas locais (chaebols) e em grandes investimentos em P\&D (KIM, 2005). Já em países como Brasil e México, o governo foi o principal agente de desenvolvimento, adotando estratégias protecionistas e de substituição de importações para o desenvolvimento de competências locais por meio de aprendizagem (LALL, 1992; KATZ, 2000).

No início dos anos 90, o fim dessas estratégias e a abertura de mercado acarretaram fortes mudanças estruturais nesses países, elevando as taxas de desemprego e exigindo maior nível de capacitação dos profissionais, pelo aumento da concorrência com empresas estrangeiras sediadas no mercado doméstico. Apesar das dificuldades para a adequação ao novo contexto, o papel dos governos continuou sendo fundamental para o desenvolvimento tecnológico.

No Brasil, a Lei da Informática, criada em 1991 para incentivar a produção de equipamentos de informática e telecomunicações, atraiu grandes empresas multinacionais e fomentou a criação de institutos de pesquisa por parte dessas empresas, promovendo sua interação com universidades, difundindo conhecimento e reduzindo custos para o desenvolvimento de $\mathrm{P} \& \mathrm{D}$ no País, acarretando acumulação de competências tecnológicas (FIGUEIREDO, 2006).

Nos países emergentes, a utilização de patentes como medida principal de inovação é questionada por alguns autores, que consideram mais importante levar em consideração os esforços de aprendizagem e capacitação. Figueiredo (2003) sugere uma métrica alternativa, adaptada de Lall (1992) e Bell e Pavitt (1995), baseada no conceito de aprendizagem tecnológica, que inclui os vários processos pelos quais o conhecimento tácito dos indivíduos é transformado em sistemas físicos, processos de produção, procedimentos, rotinas e serviços da organização. Essa métrica distingue competências rotineiras de competências inovadoras.

Inclui justificativa e benefícios decorrentes.

O objetivo deste artigo é elaborar uma estrutura conceitual e analítica, com base em modelo desenvolvido por Figueiredo (2003) e adaptada ao setor de serviços, aplicando-a em um estudo de caso na Companhia do Metropolitano de São Paulo, aqui denominada Metrô SP, cujas funções técnicas assemelham-se àquelas encontradas em setores industriais. Por meio dessa estrutura, é apresentada a trajetória de acumulação de competências tecnológicas 
e a influência dos processos de aprendizagem sobre tal trajetória. A escolha do tema justifica-se pela escassez de trabalhos relevantes publicados a partir dos anos 90 sobre trajetória de acumulação de competências tecnológicas (LALL, 1992; BELL; PAVITT, 1995; KIM, 1997, 1998, 2005; FIGUEIREDO, 2003; TACLA; FIGUEIREDO, 2003; entre outros).

Além disso, Figueiredo (2003) avalia que poucos analisam os impactos promovidos pelos processos de aprendizagem nessa trajetória. Miranda e Figueiredo (2010) também ressaltam a escassez de estudos para examinar a dinâmica de acumulação de competências tecnológicas.

Em geral, os estudos desenvolvidos sobre este tema têm se concentrado no setor industrial (LALL, 1992; KIM, 1997, 1998, 2005; KATZ, 2000; TACLA; FIGUEIREDO, 2003; FIGUEIREDO, 2003; entre outros), investigando a contribuição da obtenção de competências tecnológicas para a melhoria de desempenho operacional e competitividade nas empresas. No Brasil, apenas recentemente foram desenvolvidos estudos sobre a influência dos processos de aprendizagem na trajetória de acumulação de competências tecnológicas no setor de serviços (MIRANDA; FIGUEIREDO, 2010), existindo a necessidade do desenvolvimento de maior quantidade de estudos desta natureza.

O estudo de caso analisou o período entre 1968 e 2010, desde a fundação da empresa, passando pela época referente à política de substituição de importações e à posterior abertura de mercado. Com isto, foi possível aplicar a estrutura conceitual e analítica elaborada na verificação de aspectos relacionados à transferência de tecnologia externa para a empresa, bem como de seus processos subsequentes de aprendizagem que, por sua vez, influenciaram a acumulação de competências tecnológicas.

\section{Conceitos de competências tecnológicas e aprendizagem nas empresas}

A revisão da literatura presente neste artigo apresenta a evolução de estudos relacionados à acumulação de competências tecnológicas por parte de empresas e países, bem como a relevância da aprendizagem tecnológica neste processo. A transferência tecnológica é retratada como fator fundamental para o processo de aprendizagem e acumulação de competências tecnológicas em países em desenvolvimento.

\subsection{Competências tecnológicas}

Desde a década de 1970, diversos estudos abordaram a construção e acumulação de competências tecnológicas, especialmente em países emergentes
(DAHLMAN; FONSECA, 1978; BELL, 1985; DAHLMAN; ROSS-LARSSON; WESTPHAL, 1987), mas, em geral, apresentam uma visão restrita do conceito de competência tecnológica. A partir dos anos 1990, com a abertura dos mercados e a intensificação da globalização e concorrência mundial, surgiram estudos que examinavam a influência dos processos de aprendizagem na acumulação de competências tecnológicas (LALL, 1992; BELL; PAVITT, 1995; FIGUEIREDO, 2003).

Vários autores estudaram a acumulação de competências tecnológicas e processos de aprendizagem em países de diferentes estágios de desenvolvimento. Nos países centrais, enfatizam-se o papel do conhecimento prévio para a assimilação de novos conhecimentos -capacidade absortiva (COHEN; LEVINTHAL, 1990) -; os processos de conversão do âmbito individual para o organizacional (NONAKA; TAKEUCHI, 1997); sua introdução nas rotinas organizacionais; e sua integração às competências tecnológicas já acumuladas, fortalecendo-as (LEONARD-BARTON, 1995; TEECE, PISANO; SHUEN, 1997). Entretanto, esses estudos não abordam a forma e o tempo despendido no desenvolvimento e acumulação dessas competências no longo prazo e nem os aspectos relacionados à transferência tecnológica, dado seu enfoque em países desenvolvidos (FIGUEIREDO, 2003).

\subsection{Aprendizagem nas empresas}

A aprendizagem é um processo de mudança com base em experiências anteriores acumuladas, que podem resultar em mudanças de comportamento (FLEURY; FLEURY, 1997). A literatura descreve vários tipos de aprendizagem, como mostra o Quadro 1.

Porém, o simples reconhecimento desses mecanismos não permite examinar a sua influência na construção e acumulação de competências tecnológicas. Nesse caso, trata-se de "aprendizagem tecnológica", relacionada aos processos que promovem a aquisição de conhecimentos, bem como à incorporação dos conhecimentos adquiridos pelos indivíduos no nível organizacional (FIGUEIREDO, 2003). A aprendizagem tecnológica refere-se a processos de conversão da aprendizagem individual em aprendizagem organizacional.

Os trabalhos relativos aos países em desenvolvimento focalizam empresas e setores industriais, classificando-os em uma condição inicial de baixa competitividade no mercado mundial, período caracterizado como "infância industrial", em que a aquisição e acumulação de competências tecnológicas constituem a estratégia para atingir um estágio superior. O processo de transferência de tecnologia a partir de países desenvolvidos é fundamental para a 
Quadro 1. Mecanismos de aprendizagem.

\begin{tabular}{|c|c|}
\hline Mecanismo de aprendizagem & Características do mecanismo de aprendizagem \\
\hline Learning by doing & $\begin{array}{l}\text { Manifesta-se por uma postura passiva, automática e sem custos adicionais, com } \\
\text { base no feedback de atividades produtivas. É insuficiente para a construção de } \\
\text { competências que levem ao desenvolvimento tecnológico, mas suficiente para a } \\
\text { excelência operacional. }\end{array}$ \\
\hline Learning by using & $\begin{array}{l}\text { Consiste na acumulação de conhecimento que decorre do uso de determinado } \\
\text { produto, e não de seu processo de fabricação. Em relação ao anterior, envolve mais } \\
\text { ação por parte dos usuários, gerando maior eficiência e minimização de custos. }\end{array}$ \\
\hline Learning by changing & $\begin{array}{l}\text { Manifesta-se sempre que ocorrem mudanças de forma sistemática nas } \\
\text { características da operação de uma empresa. O ritmo de aprendizagem não se } \\
\text { relaciona diretamente ao tempo ou à produção, mas à taxa de modificações e } \\
\text { novos projetos implantados. }\end{array}$ \\
\hline Learning by hiring & Contratação de profissionais com conhecimentos inexistentes na empresa. \\
\hline Learning by training & Aprendizagem por meio de treinamentos. \\
\hline Learning by searching & $\begin{array}{l}\text { É a busca por transferência de tecnologia que, por sua vez, depende de esforço } \\
\text { interno da empresa e do conhecimento prévio acumulado, para adaptá-la às } \\
\text { necessidades locais. }\end{array}$ \\
\hline $\begin{array}{l}\text { Learning by system } \\
\text { performance feedback }\end{array}$ & $\begin{array}{l}\text { Manifesta-se com a utilização de sistemas institucionalizados para geração, registro, } \\
\text { análise e interpretação de informações referentes ao desempenho operacional, } \\
\text { construindo memória organizacional para evitar a replicação de falhas anteriores. }\end{array}$ \\
\hline Learning by learning & Aumento da própria capacidade de aprender, resultante da acumulação de capacidades. \\
\hline
\end{tabular}

Fonte: adaptado de Fleury e Fleury (1997), Bell e Pavitt (1985) e Queiroz (2006).

trajetória de construção e acumulação de competências tecnológicas locais.

Vários autores desenvolveram modelos para análise dessa trajetória, destacando-se os trabalhos de Lall (1992) e Bell e Pavitt (1995), que enfatizam a reunião simultânea de investimentos físicos, recursos humanos e seus conhecimentos e experiências individuais, bem como de esforços voltados para a construção das competências necessárias para gerar e gerenciar mudanças tecnológicas. Kim (2005) utiliza o termo "aptidão tecnológica" para definir a capacidade de assimilar, utilizar, adaptar e mudar tecnologias existentes, num processo contínuo e consistente de aprendizagem. O caráter tácito da tecnologia requer processos de aprendizagem para gerar condições para transferência efetiva.

Bell e Pavitt (1995) enfatizam as diferenças entre competências básicas de produção e competências inovadoras, necessárias para a criação e gerenciamento de mudanças técnicas e propuseram um modelo composto por seis funções técnicas, estabelecendo critérios para definir níveis de competência básica e inovadora para cada uma das funções.

Com base nos modelos de Lall (1992) e Bell e Pavitt (1995) e Figueiredo (2003) propôs uma estrutura conceitual e analítica que permite o estudo da trajetória de acumulação de competências tecnológicas e a influência dos processos de aprendizagem nessa trajetória. Inicialmente aplicado em siderúrgicas, esse modelo, que se mostrou eficaz na análise de diferenças quanto ao tempo e à forma de acumulação de competências tecnológicas e da influência da aprendizagem, define os seguintes processos de aprendizagem:

- Aquisição do saber externo: obtenção de conhecimento fora da empresa, como treinamentos externos, visitas técnicas e cursos em universidades e outras instituições;

- Aquisição do saber interno: relacionado à obtenção de conhecimento dentro da empresa, como atividades de pesquisa e desenvolvimento de produtos;

- Socialização do saber: conversão de conhecimentos tácitos, do âmbito individual para o organizacional, por meio de treinamentos internos, reuniões e palestras na empresa;

- Codificação do saber: conversão de conhecimentos explícitos, do âmbito individual para o organizacional, mediante a elaboração de documentação técnica, normas e procedimentos, relatórios e materiais de apoio em palestras e treinamentos.

Esses quatro processos de aprendizagem são analisados com base em quatro características-chave, assim definidas:

- Variedade: diversidade de iniciativas relacionadas aos processos de aprendizagem para a conversão do conhecimento individual em organizacional;

- Intensidade: frequência com que se aplicam os processos de aprendizagem ao longo do tempo, 
objetivando a conversão de aprendizagem individual em organizacional;

- Funcionamento: modo como os processos de aprendizagem ocorrem ao longo do tempo, influenciando diretamente as características variedade e intensidade;

- Interação: modo como os processos de aprendizagem interagem.

A grande contribuição desse modelo foi o preenchimento de lacunas existentes nos estudos anteriores em países desenvolvidos e emergentes, contribuindo para a realização de estudos de caso longitudinais. Sua aplicação permite verificar a criação, obtenção e até retrocesso nos níveis de competências rotineiras e inovadoras.

\section{Procedimentos metodológicos}

Foi utilizada abordagem qualitativa, com pesquisa de caráter exploratório e descritivo, uma vez que se apresenta a história da empresa, com ênfase na evolução das funções técnicas de operação, manutenção e gestão de projetos. Para tal, foi empregado o método do estudo de caso (YIN, 2005).

A escolha do Metrô SP foi definida pela necessidade de analisar o setor de serviços públicos, no qual se pudesse observar a transferência de tecnologia internacional e a aprendizagem para a formação de competências. Além disso, a empresa escolhida deveria ter sido fundada antes de 1990, de forma a apresentar histórico com, no mínimo, 20 anos de operação, período suficiente para verificar a acumulação de competências tecnológicas e processos de aprendizagem ao longo do tempo. Buscou-se identificar tópicos comuns, com o fim de classificá-los na estrutura adaptada de Figueiredo (2003), desenvolvida para este estudo de caso e que possibilitou a análise dos níveis de competências tecnológicas acumuladas nas funções técnicas Gestão da Operação, Gestão da Manutenção e Concepção e Gestão de Projetos, conforme mostra o Quadro 2.

A análise histórica foi realizada por meio de pesquisa documental, utilizando-se Relatórios de Administração e Relatórios de Operação disponíveis na biblioteca da empresa, pesquisa bibliográfica em revistas especializadas no segmento, publicadas desde 1974 e pesquisas no site da empresa. Foram também realizadas entrevistas com quatro colaboradores, em funções de gestão nas áreas de Operação, Manutenção e Projetos. Os dados coletados nas entrevistas e documentos foram analisados e interpretados mediante a técnica de análise de conteúdo (BARDIN, 2006). As entrevistas foram semiestruturadas com base em roteiro previamente elaborado (CRESWELL, 1998), conforme Apêndice 1.

Foi realizada reunião inicial para detalhamento dos objetivos da pesquisa e indicação dos entrevistados.
Estes deveriam ter no mínimo 20 anos de experiência acumulada em áreas de Projeto, Manutenção ou Operação da empresa, atuando ao longo desse período em cargos considerados estratégicos. Alguns dos entrevistados participaram da implantação da Linha Azul (a primeira linha), tendo realizado estágios e visitas técnicas em fornecedores internacionais e em metrôs de outros países. Os que ingressaram após a implantação dessa linha puderam vivenciar a construção e expansão das linhas Vermelha e Verde.

Os critérios para análise das quatro característicaschave em cada processo de aprendizagem foram assim definidos: considerou-se baixa variedade um número menor do que 10 iniciativas, e alta variedade acima de 20 iniciativas. Esta escala se justifica com base em estudo anterior (TACLA; FIGUEIREDO, 2003), que definia como "alta" variedade, um total de 10 ou mais iniciativas. Uma vez que o caso estudado coincide com o surgimento de um segmento metroviário nacional, até então inexistente e que exigiu grande ênfase em aprendizagem, definiu-se uma escala em que 10 iniciativas representassem uma variedade considerada apenas "moderada", tornando-se "alta" apenas quando superior a 20 iniciativas.

$\mathrm{O}$ número de interações entre as iniciativas de aprendizagem em relação ao total de interações possíveis variou de $<0,2$ (fraca) a $>0,7$ (forte). A interação é dada pela relação direta entre os processos de aprendizagem identificados, calculando-se todas as interações possíveis e comparando-se às interações existentes, o que determina o grau de interação em cada período analisado no estudo de caso. A forma de cálculo das interações e a escala constituem novidade em relação aos trabalhos anteriores desta natureza.

A frequência dos processos de aprendizagem variou de baixa intensidade (processo raramente aplicado, de forma pontual e esporádica no período analisado) a intermitente (processo aplicado eventualmente, sem frequência definida no período analisado) e contínua (processo aplicado de forma contínua e sistemática, com frequência definida ou em diversas ocasiões no período analisado). Esta escala foi adotada a partir de Tacla e Figueiredo (2003).

O funcionamento moderado envolvia "processos de aprendizagem pautados por um baixo ou médio grau de eficácia, gerando retrabalhos eventuais e evolução ao longo da curva de aprendizado"; enquanto o bom funcionamento consistia de "processos de aprendizagem de alta eficácia, sem necessidade de retrabalhos, que proporcionam curva de aprendizado mais acentuada". A escala elaborada considerou a eficácia das iniciativas de aprendizagem.

Assim, o funcionamento de uma iniciativa é considerado "bom" se apresentar resultados eficazes, por meio de uma sólida base de conhecimento e dispensando retrabalhos. Para os casos em que a iniciativa teve de ser refeita, envolvendo retrabalhos 
Quadro 2. Modelo de análise de competências tecnológicas no Metrô SP.

\begin{tabular}{|c|c|c|c|}
\hline \multirow[t]{2}{*}{ Níveis } & $\begin{array}{c}\text { Concepção e gestão de } \\
\text { projetos }\end{array}$ & Gestão da operação & Gestão de manutenção \\
\hline & \multicolumn{3}{|c|}{ Competências tecnológicas de rotina } \\
\hline 1. Básica & $\begin{array}{l}\text { Desenvolvimento de } \\
\text { estudos de viabilidade } \\
\text { técnica e econômica do } \\
\text { projeto, sob supervisão } \\
\text { externa. }\end{array}$ & $\begin{array}{l}\text { Operação básica de uma rede de } \\
\text { metrô sob orientação externa. }\end{array}$ & $\begin{array}{l}\text { Realização de manutenções } \\
\text { corretivas e reposições } \\
\text { rotineiras de componentes e } \\
\text { equipamentos, sob orientação } \\
\text { externa. }\end{array}$ \\
\hline \multirow[t]{2}{*}{ 2. Renovada } & \multirow[t]{2}{*}{$\begin{array}{l}\text { Desenvolvimento de } \\
\text { estudos de viabilidade } \\
\text { técnica e econômica, } \\
\text { participando de projetos } \\
\text { e especificando sistemas } \\
\text { sob supervisão externa. }\end{array}$} & $\begin{array}{l}\text { Operação básica de uma rede de } \\
\text { metrô. }\end{array}$ & $\begin{array}{l}\text { Realização de manutenções } \\
\text { corretivas e reposições } \\
\text { rotineiras de componentes e } \\
\text { equipamentos. Competência } \\
\text { para realizar testes de } \\
\text { desempenho em equipamentos. }\end{array}$ \\
\hline & & \multicolumn{2}{|c|}{ Competências tecnológicas inovadoras } \\
\hline $\begin{array}{l}\text { 3. Extrarre- } \\
\text { novada }\end{array}$ & $\begin{array}{l}\text { Desenvolvimento e } \\
\text { execução de Pesquisas } \\
\text { origem-destino. } \\
\text { Competência para } \\
\text { identificar e analisar novas } \\
\text { tecnologias no segmento. }\end{array}$ & $\begin{array}{l}\text { Desenvolvimento de estudos para } \\
\text { melhorar eficiência operacional, } \\
\text { promovendo pequenas adaptações e } \\
\text { melhorias incrementais na operação } \\
\text { e avanços tecnológicos de maior } \\
\text { complexidade, sob supervisão externa. }\end{array}$ & $\begin{array}{l}\text { Elaboração de especificações } \\
\text { de componentes e } \\
\text { equipamentos, realizando } \\
\text { reformas em equipamentos de } \\
\text { alta complexidade tecnológica } \\
\text { sob supervisão externa. }\end{array}$ \\
\hline $\begin{array}{l}\text { 4. Pré- } \\
\text { intermediária }\end{array}$ & $\begin{array}{l}\text { Elaborar e participar em } \\
\text { projetos, especificando } \\
\text { sistemas e equipamentos, } \\
\text { liderando equipes } \\
\text { multidisciplinares e } \\
\text { fornecedores, com suporte } \\
\text { técnico externo. }\end{array}$ & $\begin{array}{l}\text { Desenvolvimento de estudos para } \\
\text { melhorar eficiência operacional, } \\
\text { promovendo adaptações e melhorias } \\
\text { incrementais na operação e } \\
\text { desenvolvendo novas tecnologias } \\
\text { em conjunto com outras empresas, } \\
\text { apoiando projetos para sua implantação } \\
\text { e aplicação na operação existente. }\end{array}$ & $\begin{array}{l}\text { Realização de reformas e } \\
\text { especificações relacionadas a } \\
\text { componentes e equipamentos } \\
\text { de média e alta complexidade } \\
\text { tecnológica, além de atividades } \\
\text { de administração de materiais. } \\
\text { Realização de programas de } \\
\text { manutenção preventiva. }\end{array}$ \\
\hline \multicolumn{4}{|c|}{ Competências tecnológicas inovadoras } \\
\hline 5. Intermediária & \begin{tabular}{|l|} 
Assessoria a outras \\
empresas do segmento, no \\
que tange ao planejamento \\
e execução de projetos \\
básicos de metrôs pesados \\
de menor porte.
\end{tabular} & $\begin{array}{l}\text { Assessoria a outras empresas do } \\
\text { segmento, que operam metrôs } \\
\text { pesados de menor porte. Competência } \\
\text { para identificar e assimilar novas } \\
\text { tecnologias com apoio externo, para } \\
\text { aplicação na operação existente. }\end{array}$ & $\begin{array}{l}\text { Assessoria a outras empresas } \\
\text { do segmento, que operam } \\
\text { metrôs pesados de menor porte. } \\
\text { Competência para identificar } \\
\text { e assimilar novas tecnologias } \\
\text { com apoio externo, aplicando- } \\
\text { as na operação existente. }\end{array}$ \\
\hline 6. Média-alta & $\begin{array}{l}\text { Implementar inovações } \\
\text { incrementais e radicais } \\
\text { em sistemas, assimilando } \\
\text { novas tecnologias. }\end{array}$ & $\begin{array}{l}\text { Implementação de melhoria } \\
\text { contínua de processos e técnicas de } \\
\text { gestão organizacional. Referência } \\
\text { mundial, com padrões de excelência } \\
\text { internacionais. }\end{array}$ & $\begin{array}{l}\text { Implementação de melhoria } \\
\text { contínua de processos e gestão } \\
\text { organizacional. Referência } \\
\text { mundial com padrões de } \\
\text { excelência internacionais. }\end{array}$ \\
\hline 7. Avançada & $\begin{array}{l}\text { Referência mundial em } \\
\text { assessoria, planejamento, } \\
\text { e execução de projetos } \\
\text { básicos para metrôs } \\
\text { pesados de grande porte. }\end{array}$ & $\begin{array}{l}\text { Desenvolvimento com outras } \\
\text { empresas, de novas tecnologias } \\
\text { para o segmento. Polo mundial } \\
\text { de difusão de pesquisa e novas } \\
\text { tecnologias para o segmento. }\end{array}$ & $\begin{array}{l}\text { Desenvolvimento, com outras } \\
\text { empresas, de novas tecnologias } \\
\text { para o segmento. Polo mundial } \\
\text { de difusão de pesquisa e novas } \\
\text { tecnologias para o segmento. }\end{array}$ \\
\hline
\end{tabular}

Fonte: Elaboração própria, com base em Figueiredo (2003).

para consolidação da aprendizagem, a característica funcionamento foi considerada "moderada".

O alcance de cada nível de competência tecnológica foi mensurado em anos, e caracterizado pelo desenvolvimento e implantação de inovações que atendiam aos quesitos estabelecidos no modelo conceitual adotado. Foram considerados dois períodos distintos da história do Metrô SP. O primeiro período, entre 1968 e 1974, foi a pré-operação, iniciada com a fundação da empresa e marcada pela transferência tecnológica e um intenso processo de aprendizagem em tecnologias até então inexistentes no País. O ano de 1974 marca o final desse período, com a 
implantação da Linha Azul e início da operação comercial do Metrô SP.

O segundo período analisado, entre 1975 e 2010, refere-se à operação comercial e é caracterizado pela sedimentação da base de conhecimento construída no período anterior, que possibilitou a introdução de uma série de inovações a partir da implantação da Linha Azul. Em relação à abrangência do estudo de caso, foram analisados dados referentes à implantação e operação comercial das linhas Azul, Vermelha, Verde e Lilás, operadas diretamente pelo Metrô SP.

\section{Apresentação dos resultados: Companhia do Metropolitano de São Paulo (Metrô SP)}

Fundado em 1968, o Metrô SP é uma empresa vinculada à Secretaria de Transportes Metropolitanos do Estado de São Paulo, responsável pela gestão de quatro linhas, que percorrem $65,3 \mathrm{~km}$ de extensão e 58 estações (dados de 2010) (COMPANHIA..., 2010). Além disso, firmou uma parceria público-privada com o Consórcio Via Quatro, responsável pela instalação de equipamentos, trens e operação da Linha Amarela, que não foi abordada neste estudo.

A empresa contava, em 2010, com um total de 8.740 funcionários, sendo $80 \%$ alocados nas áreas de Operação e Manutenção, integrando a Diretoria de Operações. Atualmente, o organograma da empresa compreende 6 diretorias: Diretoria de Assuntos Corporativos; Diretoria de Engenharia e Construções; Diretoria de Finanças; Diretor de Operações; e Diretoria de Planejamento e Expansão dos Transportes Metropolitanos (COMPANHIA..., 2012).

\subsection{Processos de aprendizagem no metrô de São Paulo - 1968 a 1974}

O período entre 1968 e 1974 foi marcado por forte dependência tecnológica e intenso processo de aprendizagem. Para a implantação da primeira linha, a empresa optou por buscar tecnologias de ponta, mesmo com carência de mão de obra brasileira especializada para viabilizar o empreendimento (CARMIGNANI, 1988). Eram necessários arquitetos e urbanistas, engenheiros civis para elaboração de projetos de túneis sob uma região de alta densidade demográfica, e engenheiros elétricos e eletrônicos, para implantação de sistemas automáticos de controle de trens e alimentação elétrica (ASSMANN, 1988).

Para viabilizar a implantação do Metrô SP, foi fundado, em 1966, o Grupo Executivo Metropolitano (GEM), formado pelo diretor do Instituto de Engenharia de São Paulo e por assessores do prefeito. O GEM coordenou o processo de concorrência para a contratação do consórcio HMD (formado pelas empresas alemãs Hotchief e Dconsult e pela brasileira Montreal), responsável pela elaboração e acompanhamento do projeto básico da rede.

A primeira pesquisa Origem-Destino, realizada em 1967, identificou os principais corredores da cidade e concebeu o projeto básico da rede para a cidade de São Paulo, definindo linhas, localização e tamanho de estações. Uma vez contratado o consórcio, o GEM foi extinto, surgindo, em 1968, a empresa Metrô SP, para implantar e operar a rede projetada. Em 1974, com o apoio do consórcio HMD, a empresa já acumulava experiência para especificar, elaborar e coordenar projetos de construção de linhas de metrô subterrâneas e em elevado.

Desde o início, a premissa era obter domínio tecnológico. Assim, ocorreu intenso processo de aprendizagem por parte da empresa e de fornecedores locais, em relação às tecnologias do setor (REVISTA ENGENHARIA, 2009). Apesar da dependência tecnológica, o Metrô SP sempre participou ativamente na coordenação do projeto de implantação da Linha Azul, nas decisões e estudos de soluções alternativas. Para isso, iniciou a formação de equipes, contratando técnicos e engenheiros de diversas especialidades com experiência também em outras áreas, como o segmento de aviação, que envolvia conhecimentos de segurança e controle de tráfego. Também houve participação ativa de consultores externos nas definições técnicas de projeto, métodos construtivos e sistemas, proporcionando a formação e consolidação de uma base de conhecimento técnico e desenvolvimento em engenharia.

Na construção da Linha Azul, em 1972, optou-se pelo emprego do equipamento de escavação Shield, de forma inédita na América do Sul. Mesmo sendo uma tecnologia importada, observou-se a aprendizagem do tipo learning by using, ampliando os conhecimentos locais em métodos construtivos e a experiência da empresa na elaboração e execução de projetos.

Em relação à transferência de tecnologia nesse período, destaca-se a seleção e implantação do sistema de sinalização e controle de trens. O Metrô SP optou pela importação de tecnologia de ponta, utilizada por poucas redes metroviárias na época (FREITAS; ACCURSO; MATHIAS, 1998), firmando, em 1972, um contrato com um consórcio liderado pela Westinghouse, que incluía assistência técnica por dez anos a partir do início da operação. Além de adquirir o sistema, a transferência dessa tecnologia incluiu o envio de profissionais aos fornecedores, para acompanhar o desenvolvimento do sistema, o que também possibilitou a aprendizagem necessária à implantação do Centro de Controle Operacional (CCO), conceito inédito no Brasil, e sua codificação por meio dos primeiros manuais de operação.

A aprendizagem em atividades de Operação e Manutenção ocorreu mediante estágios e visitas técnicas em fornecedores internacionais e nos metrôs 
de São Francisco e da Cidade do México. Esses profissionais foram os primeiros multiplicadores internos de conhecimento, responsáveis pela preparação de materiais didáticos e treinamentos dos demais funcionários.

Nessa fase, a empresa contou com o apoio de instituições nacionais e estrangeiras, destacando-se a UNICAMP e a Fundação para o Desenvolvimento Tecnológico de Engenharia (FDTE), ligada à Escola Politécnica da USP, que adaptaram o know-how externo às necessidades locais (CARMIGNANI, 1988; COMPANHIA..., 2011).

Outro aspecto relevante desse período foi a nacionalização de tecnologias, que elevou a engenharia nacional a um patamar de competitividade equivalente ao de empresas internacionais, na implantação de sistemas de transporte público. Apesar de utilizar alguns componentes importados, o índice de nacionalização na implantação da Linha Azul chegou a 70\% (REVISTA ENGENHARIA, 2009) e, em obras civis, alcançou o patamar de $98 \%$. Os processos de aprendizagem resultaram de visitas a fornecedores nacionais, para acompanhamento da fabricação de equipamentos e realização de testes de aceitação. Os fornecedores também promoviam treinamentos na empresa, ao introduzir as novas tecnologias, reforçando a estratégia do Metrô SP dominar cada tecnologia adquirida. Assim, em 1974, o Metrô SP inicia a operação comercial da Linha Azul.

\subsection{Competências tecnológicas no metrô de São Paulo - 1968 a 1974}

O Quadro 3 destaca o nível de competências tecnológicas rotineiras em relação à função técnica Concepção e Gestão de Projetos acumulado nesse período.

Em relação às funções técnicas Gestão de Operação e Gestão da Manutenção, o Metrô SP conseguiu acumular competências tecnológicas rotineiras ao final do período, encontrando-se apto para operar e realizar manutenções em sua linha, como mostrado no Quadro 4.

Quadro 3. Competências em Concepção e Gestão de Projetos: entre 1968 e 1974.

\begin{tabular}{|l|l|}
\hline $\begin{array}{c}\text { Níveis de } \\
\text { competências } \\
\text { tecnológicas }\end{array}$ & \multicolumn{1}{c|}{ Função Técnica - Concepção e Gestão de Projetos } \\
\cline { 2 - 3 } 1. Básica & $\begin{array}{l}\text { Competências tecnológicas de rotina } \\
\text { Metrô SP já possuía qualificação para desenvolver estudos de viabilidade com apoio externo. }\end{array}$ \\
\hline 2. Renovada & $\begin{array}{l}\text { Com a contratação do Consórcio HMD, o Metrô SP adquiriu conhecimento para elaborar } \\
\text { projetos para a construção de sua rede e participar ativamente em sua implantação. Esse nível } \\
\text { de acumulação de competências foi atingido também em 1968, com a chegada desse consórcio. }\end{array}$ \\
\hline 3. Extrarrenovada & $\begin{array}{l}\text { As pesquisas Origem e Destino contribuem de forma significativa para o planejamento de } \\
\text { futuras linhas. Em 1967, período de existência do GEM, foi realizada a primeira pesquisa } \\
\text { desse tipo. Entretanto, a acumulação desse nível de competência ocorreu em 1972, com o } \\
\text { fornecimento do sistema de sinalização e controle para a Linha Azul. Além de ser um sistema } \\
\text { vital para o Metrô SP, tratou-se de um processo de transferência tecnológica bem sucedido. }\end{array}$ \\
\hline 4. Pré-intermediária & $\begin{array}{l}\text { Os índices de nacionalização ao final do projeto de implantação da Linha Azul em um } \\
\text { patamar de 70\% comprovam que essa experiência proporcionou uma capacitação para o } \\
\text { desenvolvimento de projetos de implantação de outras linhas. }\end{array}$ \\
\hline
\end{tabular}

Fonte: Elaboração própria.

Quadro 4. Competências em Operação e Manutenção: entre 1968 e 1974.

\begin{tabular}{|l|l|c|}
\hline \multirow{2}{*}{$\begin{array}{c}\text { Níveis de } \\
\text { competências } \\
\text { tecnológicas }\end{array}$} & \multicolumn{2}{|c|}{ Competências Tecnológicas de Rotina } \\
\cline { 2 - 3 } 1. Básica & $\begin{array}{l}\text { Nível atingido com a conclusão da etapa de visitas e estágios em fornecedores e outros metrôs, } \\
\text { ou seja, mais especificamente em 1974, com a implantação da Linha Azul. }\end{array}$ \\
\hline 2. Renovada & $\begin{array}{l}\text { Até então, os profissionais do Metrô SP desenvolviam processos de aprendizagem por meio de } \\
\text { treinamentos teóricos e práticos em relação às atividades de operação e manutenção. A partir } \\
\text { de 1974, a Linha Azul sofreu expansões e sua operação e manutenção já era realizada pelos } \\
\text { profissionais do próprio Metrô SP. A empresa passou de uma etapa de treinamentos por meio de } \\
\text { estágios e visitas técnicas para a operação comercial de sua linha com autonomia. }\end{array}$ \\
\hline
\end{tabular}

Fonte: Elaboração própria. 
O consórcio HMD manteve o apoio até o final da implantação da Linha Azul, em meados de 1975, quando o Metrô SP já dispunha de conhecimento para elaboração de especificações por sua equipe técnica. Isto é evidenciado na construção da Linha Vermelha, projetada quase integralmente pela empresa e caracterizada por um grau de $90 \%$ de nacionalização de tecnologias, abrangendo a execução integral de obras civis e da via permanente por fornecedores nacionais, sob a liderança do Metrô SP. Inicia-se, portanto, após 1974, o segundo período de análise deste estudo de caso, que se caracterizou pela sedimentação do conhecimento já obtido e o desenvolvimento de competências tecnológicas inovadoras.

\subsection{Processos de aprendizagem no metrô de São Paulo - 1975 a 2010}

No início da década de 1980, um grupo formado pelo Metrô SP, metrô de Paris, UNICAMP, USP, Instituto Batelle e duas empresas privadas desenvolveu uma nova tecnologia de sinalização e controle, que substituía o uso de relês por microprocessadores, denominada CMT-MUX que consistiu no primeiro sistema de segurança de tráfego ferroviário por microprocessamento do mundo, sendo aplicado na Linha Vermelha, evidenciando uma exitosa transferência tecnológica. Nessa época, o Metrô SP já acumulava significativa base de conhecimento em atividades de Operação e Manutenção, com equipe técnica especializada e já era reconhecido internacionalmente, assessorando outros metrôs, como os de Caracas, Medellín e Rio de Janeiro (VIÉGAS, 1998). Nessas iniciativas de intercâmbio tecnológico, o Metrô SP passou a desempenhar papel inverso em relação ao primeiro período analisado, utilizando sua experiência acumulada para prestar assessoria a outros metrôs. É o caso de intercâmbios nacionais realizados junto aos metrôs de Recife e Porto Alegre - entre 1983 e 1985 - e o metrô do Rio de Janeiro, em 1997; e dos intercâmbios internacionais, com os metrôs de Bagdá e Caracas - entre 1980 e 1985 - e com o metrô de Medellín, em 1995.

A Linha Verde iniciou operação comercial em 1991, trazendo inovações em relação às linhas existentes, dentre as quais se destaca a maximização da integração entre sistemas, por meio do emprego de tecnologia de microprocessamento, centralizando informações e utilizando inteligência artificial para automatização de áreas de Operação e Manutenção (COSTA, 1988). Adotou-se uma concepção diferente de sistemas em relação às linhas Azul e Vermelha, baseada em processamento distribuído, com equipamentos ligados em rede, tornando mais ágil o tratamento de informações.

Para sustentar os índices de excelência operacional, o Metrô SP iniciou em 1992 o programa de Gestão da Qualidade Total, que exigiu um aumento na quantidade de treinamentos internos. Foram treinados mais de 500 profissionais da área de Operação e, nos dois anos seguintes, o programa foi estendido a todo o quadro operacional, contemplando mais de 3.000 funcionários. Em 2002, foi obtida a certificação do Sistema de Gestão da Qualidade para a Linha Azul, com base na ISO 9001:2000, que, no ano seguinte, foi estendido às demais linhas.

Além dos treinamentos internos, o Metrô SP promoveu parcerias com instituições de ensino e pesquisa e outras companhias de metrô em todo o mundo.

Em 1999, criou a Universidade do Metrô (UNIMETRO), com o intuito de desenvolver programas de formação de especialistas em transporte, em conjunto com instituições de ensino e empresas do segmento (COMPANHIA..., 2000).

Nesse ano, em conjunto com a Fundação Paula Souza, o Metrô SP liderou a criação de cursos técnicos de transporte e trânsito, contando com o apoio da São Paulo Transportes (SPTrans), Companhia de Engenharia de Tráfego (CET), ANTP e CPTM.

Outra iniciativa importante em relação aos processos de aprendizagem foi a implantação da Intranet corporativa. Em 2001, essa ferramenta consolidou-se definitivamente, passando a ser denominada Metroweb, tornando-se um meio de comunicação de informações para toda a empresa (COMPANHIA..., 2002). Ainda em 2001, foi criado o Programa de Excelência Gerencial - PEG, desenvolvido pela UNIMETRO em parceira com a Fundação Instituto de Administração (FIA), responsável pela formação de várias turmas de profissionais da empresa, em cargos gerenciais e técnicos. Com o Centro Estadual de Educação Tecnológica Paula Souza (CEETEPS), o Metrô SP estabeleceu convênio para criação do Curso de Capacitação Técnica em Transporte Metropolitano sobre Trilhos, com o intuito de capacitar seus profissionais no desempenho de funções de supervisão de estações, centro de controle, planejamento de transporte, projetos e pesquisas sobre o segmento.

Também se destacam as parcerias com o SENAI e com o CIEE (Centro de Integração Empresa-Escola), esta para seleção de estagiários. Em 2010, foram 250 mil horas de treinamento, sendo a maior parte destinada a atividades que envolviam tecnologia e desenvolvimento (COMPANHIA..., 2011).

$\mathrm{O}$ foco em capacitação contínua e a introdução de inovações tecnológicas incentivaram o aumento do grau de escolaridade dos profissionais do Metrô SP. Entre 2000 e 2010, aqueles com escolaridade até o ensino médio passaram de $76 \%$ do total para $66 \%$, ao passo que os de nível superior cresceram de $24 \%$ para 34\% (COMPANHIA..., 2004, 2005, 2007, 2010). Eles buscaram capacitação externa e permaneceram na empresa, cujo quadro de colaboradores possui 
metade com idade acima de 45 anos e média de tempo de serviço de 17 anos.

Com base nesses dados, constata-se que o Metrô SP conta com funcionários bastante experientes. A formação dessa sólida base de conhecimento e experiência vem ocorrendo desde a fundação da empresa, quando não existia este segmento no País. Assim, a orientação de desenvolvimento tecnológico adotado pela empresa e os consequentes processos de aprendizagem foram fundamentais para a construção dessa base. Conforme apontaram os dados coletados, a empresa promove treinamentos de forma sistemática, além de codificar o conhecimento acumulado, permitindo sua transferência para os funcionários mais novos.

É importante destacar ainda a prospecção contínua, ao longo da história da empresa, de novas tecnologias, voltadas ao aumento da capacidade de transporte, como o CBTC (Communication-Based Train Control), que possibilita a diminuição dos intervalos entre trens. Implantada em 2010, no novo trecho da Linha Verde, sua prospecção ocorreu por meio de visitas técnicas a fornecedores e participação em congressos do segmento metroviário. A participação da empresa como integrante do CoMET (Comunidade de Metrôs) também contribuiu para o aprendizado em relação às funções técnicas de Operação e Manutenção, por meio da prática de benchmarking.

\subsection{Competências tecnológicas no metrô de São Paulo - 1975 a 2010}

A partir de 1975, com a implantação da Linha Azul, a empresa iniciou um processo de acumulação de competências tecnológicas inovadoras, ilustradas nos Quadros 5 e 6, na Tabela 1 e na Figura 1. Os gráficos (Figura 2) seguintes apresentam a evolução dos processos de aprendizagem do primeiro para o segundo período, por meio das quatro características-chave.

\section{Análise e discussão dos resultados}

A implantação do Metrô SP exigiu uma etapa inicial de transferência de tecnologia dos Estados Unidos e Alemanha. Porém, por enfatizar a capacitação tecnológica desde o início, a transferência não se limitou à aquisição de sistemas e equipamentos, incluindo processo intenso de aprendizagem, mediante estágios e visitas técnicas, além do apoio do consórcio HMD na elaboração e execução do projeto de implantação da primeira linha. Os esforços empregados na acumulação de competências tecnológicas foram claramente evidenciados no Metrô SP, que não optou pela aquisição de pacotes de implantação, manutenção e operação, mas por atingir índices crescentes de nacionalização de projetos, sistemas e equipamentos, como a sinalização e controle da Linha Azul e a fabricação local de trens pela Mafersa.

Vários mecanismos de aprendizagem descritos por Fleury e Fleury (1997) foram observados. Learning by doing e learning by using estiveram presentes no dia a dia dos funcionários, desde o início do projeto, ao utilizar os equipamentos importados, e aprender a operá-los, como também nas etapas de manutenção correspondentes. Learning by changing é evidenciado na introdução de novas tecnologias na construção de cada linha da rede. O mecanismo learning by training foi praticado pela empresa desde a sua fundação, por

Quadro 5. Competências em Concepção e Gestão de Projetos: entre 1975 e 2010.

\begin{tabular}{|l|l|}
\hline $\begin{array}{c}\text { Níveis de } \\
\text { competências } \\
\text { tecnológicas }\end{array}$ & \multicolumn{1}{c|}{ Função Técnica - Concepção e Gestão de Projetos } \\
\cline { 2 - 3 } & \multicolumn{1}{c|}{ Competências tecnológicas inovadoras } \\
\hline 5. Intermediária & $\begin{array}{l}\text { Além de treinamento de operação e manutenção para outros metrôs de menor porte, a partir de } \\
\text { 1984 o Metrô SP iniciou trabalhos de consultoria na elaboração de projetos para implantação } \\
\text { de metrôs em outras cidades. Evidencia-se isto com os intercâmbios tecnológicos promovidos } \\
\text { para a elaboração de projetos de metrôs para as cidades de Salvador e Bagdá. Assim, em 1984, a } \\
\text { empresa já acumulava esse nível de competência tecnológica para a função técnica Concepção e } \\
\text { Gestão de Projetos. }\end{array}$ \\
\hline 6. Média-alta & $\begin{array}{l}\text { A construção da Linha Verde, finalizada em 1991, trouxe uma série de inovações, e o Metrô } \\
\text { SP consolidou seu aprendizado em relação aos métodos construtivos existentes. Além disso, a } \\
\text { experiência anterior, com o desenvolvimento do sistema de sinalização e controle, em conjunto } \\
\text { com instituições nacionais e estrangeiras, foi aplicada na implantação dessa linha. Esse nível } \\
\text { de competência tecnológica para a função técnica Concepção e Gestão de Projetos foi mantido, } \\
\text { viabilizando a prospecção e introdução de tecnologias Portas de Plataforma e CBTC. }\end{array}$ \\
\hline 7. Avançada & $\begin{array}{l}\text { Apesar de sua extensa base de conhecimento e a aplicação de tecnologias de ponta em sua } \\
\text { operação, o Metrô SP não vivenciou, de forma contínua, experiências no planejamento e } \\
\text { execução de projetos básicos para redes de metrô de maior porte. Mesmo dispondo de tecnologia } \\
\text { de ponta, ainda não atingiu esse nível de competências para esta função técnica. }\end{array}$ \\
\hline
\end{tabular}

Fonte: Elaboração própria. 
Quadro 6. Competências em Operação e Manutenção: entre 1975 e 2010.

\begin{tabular}{|c|c|c|}
\hline \multirow{2}{*}{$\begin{array}{c}\text { Níveis de } \\
\text { competências } \\
\text { tecnológicas }\end{array}$} & \multicolumn{2}{|c|}{ Competências tecnológicas inovadoras } \\
\hline & Função técnica - Gestão da Operação & Função técnica - Gestão de Manutenção \\
\hline 3. Extrarrenovada & \multicolumn{2}{|c|}{$\begin{array}{l}\text { Depois do início da Linha Azul, o Metrô SP passou a desenvolver atividades de manutenção } \\
\text { de forma sistemática. Os treinamentos internos, os testes de aceitação de equipamentos e os } \\
\text { estágios no exterior proporcionaram a aquisição de conhecimento para promover manutenção } \\
\text { em equipamentos com tecnologia de ponta na época, como o sistema de sinalização e } \\
\text { controle, os equipamentos do CCO e a tecnologia chopper. Muitos equipamentos e sistemas } \\
\text { foram adquiridos com garantia de assistência técnica para os anos seguintes, contribuindo } \\
\text { para o desenvolvimento dessas manutenções. Em 1975, a empresa já acumulava esse nível } \\
\text { de competência também evidenciada pela implantação do conceito de Centro de Controle, } \\
\text { inédito no País, desde o início de sua primeira linha. }\end{array}$} \\
\hline 4. Pré-intermediária & \multicolumn{2}{|c|}{$\begin{array}{l}\text { O desenvolvimento do sistema de sinalização e controle pelo Metrô SP, em conjunto com } \\
\text { empresas nacionais e do exterior comprova a capacitação para desenvolver tecnologias e } \\
\text { aplicá-las em sua operação. Esse sistema, baseado em tecnologia de multiprocessamento, foi } \\
\text { desenvolvido para a Linha Vermelha, que iniciou sua operação em 1979, evidenciando que o } \\
\text { Metrô SP já acumulava esse nível de competência. Com a implantação da Linha Azul, surgiu } \\
\text { o Pátio de Manutenção Jabaquara, no qual já eram realizadas ativides de administração de } \\
\text { estoques e manutenções preventivas. Diferente da construção de sua primeira linha, em 1979, } \\
\text { o Metrô SP não contava mais com apoio externo do consorcio HMD, porém, dispunha de } \\
\text { conhecimento suficiente para liderar a elaboração de especificações e projetos. }\end{array}$} \\
\hline 5. Intermediária & \multicolumn{2}{|c|}{$\begin{array}{l}\text { A partir de 1980, o Metrô SP iniciou a prestação de serviços de consultoria em metrôs } \\
\text { de menor porte, localizados no País e no exterior, promovendo treinamentos técnicos nas } \\
\text { áreas de Operação e Manutenção. Considerada uma referência mundial em tecnologia } \\
\text { no segmento, o Metrô SP estava apto à identificação de novas tecnologias no mercado, } \\
\text { fato evidenciado com desenvolvimento de trens para a Linha Vermelha, em conjunto com } \\
\text { fornecedores. }\end{array}$} \\
\hline 6. Médio-alta & \multicolumn{2}{|c|}{$\begin{array}{l}\text { Em 1992, iniciou-se o projeto de implantação de um sistema de gestão baseado em } \\
\text { Qualidade Total, culminando na certificação ISO } 9000 \text { para as atividades relacionadas } \\
\text { à Manutenção e Operação. Em 1995, o Metrô SP já havia capacitado praticamente todo } \\
\text { seu quadro de Operação e Manutenção, formando também instrutores internos para } \\
\text { multiplicação do conhecimento relacionado ao sistema de gestão. A empresa aplicava os } \\
\text { conceitos de Qualidade Total, aproveitando o consistente trabalho de elaboração de padrões e } \\
\text { procedimentos de operação e manutenção desenvolvidos desde o início da Linha Azul. }\end{array}$} \\
\hline 7. Avançada & \multicolumn{2}{|c|}{$\begin{array}{l}\text { Apesar de sua extensa base de conhecimento e a aplicação de tecnologias de ponta em sua } \\
\text { operação, o Metrô SP não vivenciou, de forma contínua, experiências como polo mundial de } \\
\text { difusão de novas tecnologias para aplicação em redes de metrô de maior porte. Contudo sua } \\
\text { experiência acumulada permite a qualificação necessária para prospectar e assimilar novas } \\
\text { tecnologias desenvolvidas no mercado, como as Portas de Plataformas e o CBTC, avanços } \\
\text { tecnológicos introduzidos recentemente em sua rede. Assim, o Metrô SP ainda não atingiu } \\
\text { esse nível de competências para essas duas funções técnicas. }\end{array}$} \\
\hline
\end{tabular}

Fonte: Elaboração própria.

Tabela 1. Trajetória de acumulação de competências tecnológicas no Metrô SP (em anos).

\begin{tabular}{lccc}
\hline $\begin{array}{c}\text { Níveis de competência } \\
\text { tecnológica }\end{array}$ & $\begin{array}{c}\text { Concepção e Gestão de } \\
\text { Projetos }\end{array}$ & Gestão da Operação & Gestão de Manutenção \\
\hline (1) Básico & $\mathrm{n}=1(1968)$ & $\mathrm{n}=6(1974)$ & $\mathrm{n}=6(1974)$ \\
(2) Renovado & $\mathrm{n}=1(1968)$ & $\mathrm{n}=6(1974)$ & $\mathrm{n}=6(1974)$ \\
(3) Extra-renovado & $\mathrm{n}=4(1972)$ & $\mathrm{n}=7(1975)$ & $\mathrm{n}=7(1975)$ \\
(4) Pré-Intermediário & $\mathrm{n}=6(1974)$ & $\mathrm{n}=11(1979)$ & $\mathrm{n}=11(1979)$ \\
(5) Intermediário & $\mathrm{n}=16(1984)$ & $\mathrm{n}=12(1980)$ & $\mathrm{n}=12(1980)$ \\
(6) Médio-Alto & $\mathrm{n}=23(1991)$ & $\mathrm{n}=27(1995)$ & $\mathrm{n}=27(1995)$ \\
(7) Avançado & Não atingido & Não atingido & Não atingido \\
\hline
\end{tabular}

Fonte: Elaboração própria. 


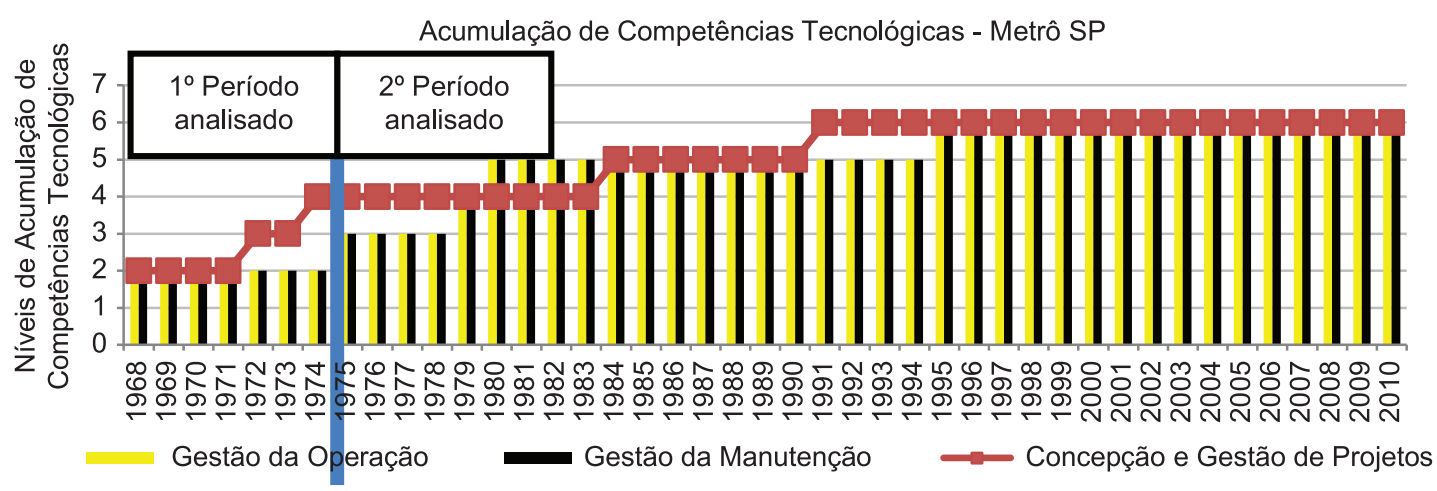

Figura 1. Trajetória de acumulação de competências tecnológicas no Metrô SP (em anos). Fonte: Elaboração própria.
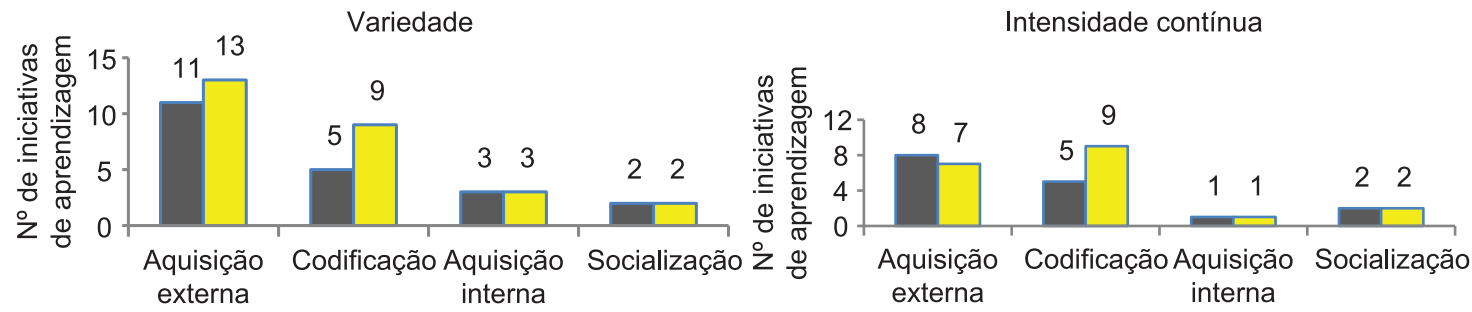

- $1968-1974 \quad 1975-2010$

๑1968-1974 ㄴ $1975-2010$
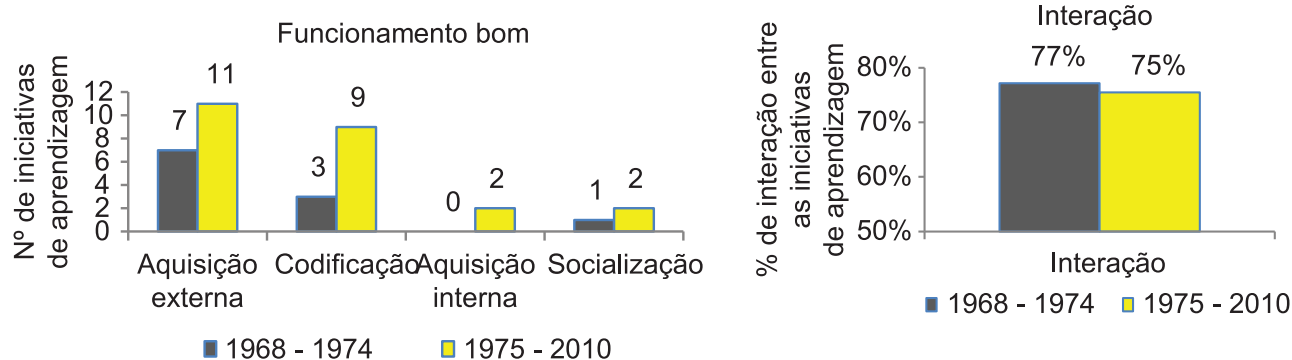

Figura 2. Características-chave dos processos de aprendizagem no Metrô SP. Fonte: Elaboração própria.

meio de treinamentos dos profissionais da empresa realizados em fornecedores, em outros metrôs e aqueles desenvolvidos internamente. Learning by hiring foi observado nos dois períodos analisados, ocorrendo em maior intensidade na fase pré-operação, quando foram contratados profissionais para as primeiras equipes técnicas. A contratação de funcionários do setor de aviação agregou experiência quanto a temas de segurança e tráfego em outros modais.

Por fim, dada a crescente capacidade absortiva da empresa, o mecanismo learning by learning (QUEIROZ, 2006) foi observado, especialmente após a implantação da primeira linha, por meio da liderança no desenvolvimento de projetos e na elaboração de especificações técnicas, à medida que a empresa absorvia novas tecnologias e promovia a transformação de conhecimento tácito em explícito.

As três funções técnicas apresentam trajetória semelhante, pois o desenvolvimento de inovações e a implantação de novas linhas foram realizados com o esforço de profissionais das áreas de Projetos, Operação e Manutenção, que formavam os times multidisciplinares, acumulando e multiplicando as experiências por toda a empresa. No primeiro período, como inexistia conhecimento relacionado à tecnologia metroviária, era fundamental a sua busca em países desenvolvidos e sua rápida codificação para permitir a difusão aos profissionais que aqui permaneceram, de forma a viabilizar o início da operação comercial do Metrô SP. Assim, esse período analisado caracterizou-se pela predominante ocorrência de processos de aprendizagem baseados em aquisição externa e codificação de conhecimento. Em relação à característica-chave intensidade, os processos de aquisição externa e codificação de conhecimentos foram desenvolvidos de forma contínua, dada a necessidade de rápida assimilação e domínio da tecnologia. Já no segundo período, observa-se que a aquisição externa de conhecimento passou a ser intermitente. É o caso de visitas técnicas a outros 
metrôs, que passaram a ser feitas não mais com o intuito de formação de base de conhecimento, mas de prospecção de novas tecnologias, benchmarking ou mesmo prestação de assessoria em treinamentos por meio de intercâmbios tecnológicos.

Em relação ao funcionamento, no primeiro período, os processos de aprendizagem apresentaram-se como moderados, uma vez que tais processos só foram realizados com maior ênfase após o início da operação comercial, quando a empresa já acumulava uma consistente base de conhecimento. Mesmo os processos de aquisição externa de conhecimento apresentavam funcionamento moderado, uma vez que a empresa experimentava seu primeiro contato com tecnologias desse segmento. No segundo período, houve significativa evolução em relação à eficácia de todos os processos de aprendizagem. Com base no conceito proposto por Cohen e Levinthal (1990), constata-se que essa melhora deveu-se principalmente à capacidade absortiva da empresa, pautada em uma consistente base de conhecimento prévio que permitiu a assimilação de novos conhecimentos, tornando mais eficazes esses processos.

Quanto à socialização, no primeiro período, ocorria um ativo compartilhamento de conhecimento tácito entre os profissionais da empresa. Com a aprendizagem adquirida no exterior e o intenso processo de codificação, a assimilação de tecnologias de ponta e a sua adaptação às condições locais permitiram um bem sucedido processo de transferência tecnológica, coerente com os conceitos de Lall (1992, 2000), Kim (2005) e Katz (2000). Vale ressaltar a importância do consórcio HMD, que proporcionou um consistente processo de aprendizagem com o apoio técnico ao projeto e a implantação de tecnologias provenientes do exterior. Sua contratação permitiu um processo de aprendizagem marcado pela forte integração com outras iniciativas, como os treinamentos no exterior e os esforços de codificação do conhecimento.

O período posterior a 1974 foi marcado pela intensificação da nacionalização de projetos e a realização de treinamentos internos, com a formação de times multidisciplinares. O Metrô SP sedimentava e atualizava sua base de conhecimento com a introdução de novas tecnologias por meio de projetos de expansão e modernização de cada linha. Todos esses processos de aprendizagem apresentaram forte interação. A possibilidade de transferir esse conhecimento para outros metrôs também gerou aprendizagem, tanto por exigir a preparação de material de treinamento, quanto pelo conhecimento de outros contextos.

Constatou-se aumento significativo do número de processos de aprendizagem. Mesmo assim, a empresa conseguiu manter forte interação entre esses processos, atingindo um patamar de $75 \%$ de interações. Outro destaque é a intensidade desses processos, realizados de forma contínua em praticamente todas as modalidades. A análise da variedade mostra o processo de aquisição externa ainda como predominante. Contudo, o volume de iniciativas de aprendizagem por fontes externas não ocorria devido à dependência tecnológica, mas sim pela realização de intercâmbios com outros metrôs, pelo maior número de convênios com universidades e empresas, além do ingresso do Metrô SP no CoMET, que proporcionou contínua aquisição de conhecimento e prospecção de novas tecnologias com base na prática de benchmarking com os maiores metrôs do mundo.

Comparando-se os processos de aprendizagem que resultaram na acumulação dessas competências nos dois períodos analisados, observa-se uma evolução ao longo do tempo em volume de iniciativas e eficácia na realização desses processos. Destaca-se a gestão por indicadores de desempenho nas áreas de Operação e Manutenção, que contribuiu para testes de aceitação de equipamentos e gestão da operação comercial, evidenciando a aprendizagem learning by perfomance system feedback, destacada por Fleury e Fleury (1997).

Os gráficos mostram significativa evolução em relação à eficácia de todos os processos de aprendizagem no segundo período analisado, devido também ao forte grau de interação, identificado ao longo da história da empresa. A Figura 2 destaca a proximidade do grau de interação entre os processos de aprendizagem nos dois períodos analisados, mantido mesmo com as dificuldades resultantes do aumento do número de iniciativas e do esforço da empresa em aprimorá-las. Assim, no primeiro período, o Metrô SP empregou intensos esforços na assimilação de conhecimentos para que pudesse implantar e operar uma tecnologia inédita no País. As fontes externas de conhecimento foram fundamentais, bem como os esforços de codificação desse conhecimento. Apesar de a função técnica Concepção e Gestão de Projetos apresentar-se em um nível maior de competência em relação às demais funções, ainda se tratava de um patamar de competência rotineira.

Ao final de 1974, a empresa já reunia qualificação necessária para elaborar e desenvolver um projeto de implantação de linhas de metrô, bem como efetuar atividades de operação e manutenção em um nível básico. A partir daquele ano, a empresa se capacitou a gerir mudanças técnicas, atingindo patamares superiores de competência em todas as funções técnicas analisadas e passando a promover inovações em sua rede, seja por introdução ou desenvolvimento de novas tecnologias, o que caracterizou a acumulação de competências tecnológicas, conforme conceitos estabelecidos por Lall (1992) e Bell e Pavitt (1995).

\section{Conclusões}

Este artigo teve por objetivo a elaboração de uma estrutura conceitual e analítica com base em modelo 
desenvolvido por Figueiredo (2003), bem como sua aplicação em um estudo de caso com foco na análise do processo de capacitação tecnológica e aprendizagem, resultantes da transferência de tecnologia de países desenvolvidos. Como objeto de análise, foi escolhida uma empresa prestadora de serviços públicos de transporte, o Metrô SP.

$\mathrm{O}$ estudo de caso do Metrô SP proporcionou uma clara compreensão dos aspectos referentes ao processo de transferência de tecnologia, capacitação e aprendizagem tecnológica. O esforço governamental foi importante para viabilizar a implantação desse modal de transporte para São Paulo e para determinar sua estratégia, focada em domínio tecnológico. O caso ilustra a busca de empresas de países emergentes pela assimilação e adaptação de tecnologias externas às condições locais.

Com base nos resultados, constata-se que os processos de aprendizagem foram fundamentais para a acumulação de competências tecnológicas pela empresa. Mesmo antes de implantar suas linhas, o Metrô SP definiu como estratégia de desenvolvimento a busca por tecnologias de ponta e a formação de uma base de conhecimento que permitisse não apenas operar e manter um sistema metroviário altamente avançado tecnologicamente, mas também que possibilitasse o desenvolvimento e a introdução de inovações incrementais e radicais. Assim, a empresa adotou um modelo voltado ao domínio tecnológico, ao invés de adquirir pacotes fechados de implantação, operação e manutenção de redes de metrô.

A busca por aprendizagem sempre foi o foco da empresa, que hoje conta com equipes de profissionais experientes e altamente especializados, bem como sistemas e equipamentos avançados, que permitem a prestação de serviços de transporte de forma extremamente eficiente. Sua orientação para o aprendizado contínuo, aliada à busca pela introdução de tecnologias de ponta, possibilitou a manutenção de uma base sólida de conhecimento, que sustentou o desenvolvimento tecnológico da empresa de forma consistente.

No primeiro período, o Metrô SP empregou intensos esforços na assimilação de conhecimentos para que pudesse implantar e operar uma tecnologia inédita no País. Assim, as fontes externas de conhecimento foram fundamentais, bem como os esforços de codificação desse conhecimento. Em 1974, a empresa já reunia qualificação necessária para elaborar e desenvolver um projeto de implantação de linhas de metrô, bem como efetuar atividades de operação e manutenção em um nível básico. A partir daquele ano, a empresa atingiu patamares superiores de competência em todas as funções técnicas analisadas, passando a promover inovações em sua rede, seja por introdução ou desenvolvimento de novas tecnologias. Além disso, a empresa se encontrava qualificada para gerir essas mudanças técnicas por meio de uma base robusta de conhecimento, caracterizando a acumulação de competências tecnológicas. Como principal contribuição deste artigo, destacamos a elaboração de uma estrutura conceitual e analítica, baseada em Figueiredo (2003), e adaptada ao setor de serviços e, mais especificamente, a casos como o do Metrô $\mathrm{SP}$, cujas funções técnicas assemelham-se àquelas encontradas em setores industriais.

\section{Referências}

ASSMANN, P. Anos de Tecnologia Metroviária. Revista do Instituto de Engenharia, n. 469, p. 14-23, jun./ ago. 1988.

BARDIN, L. Análise de Conteúdo. 3. ed. Lisboa: Edições 70, 2006.

BELL, M. Learning and the accumulation of industrial technological capacity in developing countries. In: FRANSMAN, M.; KING, K. (Org.). Technological capability in the third world. New York: Macmillan, 1985.

BELL, M.; PAVITT, K. The development of technological capabilities. In: HAQUE, I. U. (Ed.). Trade, technology and international competitiveness. Washington: World Bank, 1995. p. 69-101. PMid:8845578.

CARMIGNANI, W. A Engenharia do Metrô e Recursos Humanos. Revista do Instituto de Engenharia, n. 469, p. 58-60, jun./ago.1988.

COHEN, W. M.; LEVINTHAL, D. A. Absorptive Capacity: A New Perspective on Learning and Innovation. Administrative Science Quarterly, v. 35, n. 1, p. 128-152, Mar 1990. http://dx.doi.org/10.2307/2393553

COMPANHIA DO METROPOLITANO DE SÃO PAULO - METRÔ/SP. Relatório da Administração 1999. São Paulo, 2000.

COMPANHIA DO METROPOLITANO DE SÃO PAULO - METRÔ/SP. Relatório da Administração 2001. São Paulo, 2002.

COMPANHIA DO METROPOLITANO DE SÃO PAULO - METRÔ/SP. Relatório da Administração 2003. São Paulo, 2004.

COMPANHIA DO METROPOLITANO DE SÃO PAULO - METRÔ/SP. Relatório da Administração 2004. São Paulo, 2005.

COMPANHIA DO METROPOLITANO DE SÃO PAULO - METRÔ/SP. Relatório da Administração 2006. São Paulo, 2007.

COMPANHIA DO METROPOLITANO DE SÃO PAULO - METRÔ/SP. Relatório da Administração 2009. São Paulo, 2010.

COMPANHIA DO METROPOLITANO DE SÃO PAULO - METRÔ/SP. Histórico da Empresa. Disponível em <www.metro.sp.gov.br/ >. Acesso em 01 maio 2011.

COMPANHIA DO METROPOLITANO DE SÃO PAULO - METRO/SP. Organograma. Disponível em: <www.metro.sp.gov.br/metro/institucional/diretoria>. Acesso em: 04 nov. 2012. 
COSTA, B. L. C. Vinte anos de engenharia de sistemas do Metrô. Revista do Instituto de Engenharia, n. 469, p. 64-66, jun./ago.1988.

CRESWELL, J. W. Qualitative Inquiry and Research Design: Choosing among Five Approaches. Thousand Oaks: Sage. 1998. PMid:9566771.

DAHLMAN, C. J.; FONSECA, F. V. From technological dependence to technological development: the case of the USIMINAS Steel Plant in Brazil. IBD/ECLA Research Programme, 1978. Working paper 21.

DAHLMAN, C. J.; ROSS-LARSSON, B.; WESTPHAL, L. E. Managing Technological Development: Lessons from the Newly Industrializing Countries. World Development, v. 15, n. 6, p. 759-775, 1987. http:// dx.doi.org/10.1016/0305-750X(87)90058-1

FIGUEIREDO, P. N. Aprendizagem Tecnológica e Performance Competitiva. Rio de Janeiro: Editora FGV, 2003.

FIGUEIREDO, P. N. Acumulação tecnológica e inovação industrial: conceitos, mensuração e evidências no Brasil. Revista São Paulo em Perspectiva, v. 19, n. 1, p. 54-69, jan./mar. 2005. http://dx.doi.org/10.1590/ S0102-88392005000100005

FIGUEIREDO, P. N. Capacidade Tecnológica e Inovação em Organizações de Serviços Intensivos em Conhecimento: evidências de institutos de pesquisa em TICs no Brasil. Revista Brasileira de Inovação, v. 5, n. 2, p. 403-454, jul./dez. 2006.

FLEURY, A.; FLEURY, M. T. L. Aprendizagem e Inovação Organizacional: As experiências de Japão, Coréia e Brasil. 2. ed. São Paulo: Atlas, 1997.

FREITAS, J. H. Z.; ACCURSO, A.; MATHIAS, I. L. A evolução tecnológica da CMSP e o estado da arte de sistemas de sinalização baseado em comunicação. Revista Engenharia, n. 587, p. 116-124, mai./jun.1998.

KATZ, J. The Dynamics of Technological Learning during the Import-Substitution Period and Recent Structural Changes in the Industrial Sector of Argentina, Brazil and Mexico. In: KIM, L.; NELSON, R. N. Technology, Learning \& Innovation: Experiences of Newly Industrializing Economies. Cambridge University Press, 2000. p. 307-334.

KIM, L. The dynamics of Samsung's technological learning in semiconductors. California Management Review, v. 39, n. 3, p. 86-100, Spring 1997. http://dx.doi. org/10.2307/41165900

KIM, L. Crisis construction and organizational learning: capability building in catching-up at Hyundai Motor. Organization Science, v. 9, n. 4, p. 506-521, July/ Aug 1998. http://dx.doi.org/10.1287/orsc.9.4.506

KIM, L. Da imitação à inovação: a dinâmica do aprendizado tecnológico na Coréia. Campinas: Unicamp, 2005.

LALL, S. Technological capabilities and industrialization. World Development, v. 20, n. 2, p. 165-186, 1992. http://dx.doi.org/10.1016/0305-750X(92)90097-F

LEONARD-BARTON, D. Wellsprings of Knowledge - Building and sustaining the sources of innovation. Harvard Business School, 1995.

MIRANDA, E. C.; FIGUEIREDO, P. N. Dinâmica da acumulação de capacidades inovadoras: evidências de empresas de software no Rio de Janeiro e em São Paulo. Revista de Administração de Empresas, v. 50, n. 1, p. 75-93, jan./mar. 2010. http://dx.doi.org/10.1590/ S0034-75902010000100007

NONAKA, I.; TAKEUCHI, H. Criação de Conhecimento na Empresa: Como as Empresas Japonesas Geram a Dinâmica da Inovação. Rio de Janeiro: Campus, 1997.

QUEIROZ, S. Aprendizado Tecnológico. In: PELAEZ, V.; SZMRECSÁNYI, T. (Org.). Economia da Inovação Tecnológica. São Paulo: HUCITEC Ordem dos Economistas do Brasil, 2006. p. 193-211.

REVISTA ENGENHARIA. Edição Especial Metrô SP 35 anos de Operação. São Paulo: ano 66, n. 594, jul./ago./set. 2009.

TACLA, C. L.; FIGUEIREDO, P. N. Processos de aprendizagem e acumulação de competências tecnológicas: evidências de uma empresa de bens de capital no Brasil. Revista de Administração Contemporânea, v. 7, n. 3, p. 101-126, jul./set. 2003. http://dx.doi.org/10.1590/S1415-65552003000300006

TEECE, D. J.; PISANO, G.; SHUEN, A. Dynamic Capabilities and Strategic Management. Strategic Management Journal, v. 18, n. 7, p. 509-533, Aug 1997. http://dx.doi.org/10.1002/(SICI)10970266(199708)18:7<509::AID-SMJ882>3.0.CO;2-Z

VIÉGAS, R. O Metrô e o Intercâmbio Tecnológico. Revista Engenharia, n. 529, p. 127-129, set./out.1998.

YIN, R. K. Estudo de Caso Planejamento e Métodos. São Paulo: Bookman, 2005. 
Apêndice 1. Roteiro de Entrevista.

\begin{tabular}{|c|c|}
\hline Questões & Objetivo \\
\hline Ano em que começou a trabalhar na empresa? & - Determinação da Trajetória \\
\hline Função (ões) que desempenha (ou) na empresa? & - Determinação da Trajetória \\
\hline $\begin{array}{l}\text { Iniciou sua carreira na empresa? } \\
\text { Em caso positivo, em que áreas trabalhou? } \\
\text { Se não, quais as funções desempenhadas nas outras } \\
\text { empresas em que trabalhou? }\end{array}$ & $\begin{array}{l}\text { - Determinação da Trajetória } \\
\text { - Aquisição de Saber Externo (learning by hiring) } \\
\text { - Aquisição de Saber Interno (learning by training e } \\
\text { learning by doing) }\end{array}$ \\
\hline $\begin{array}{l}\text { Você está inserido em uma programação anual ou } \\
\text { semestral de treinamentos organizados pela empresa? } \\
\text { Os treinamentos permitem atualizar a base de } \\
\text { conhecimento necessária a sua área de atuação? }\end{array}$ & $\begin{array}{l}\text { - } 4 \text { características dos processos de aprendizagem } \\
\text { (variedade, funcionamento, intensidade e interação) }\end{array}$ \\
\hline $\begin{array}{l}\text { Quais os projetos de que participou ao longo de sua } \\
\text { carreira na empresa? } \\
\text { Quais foram suas responsabilidades nesses projetos? } \\
\text { Qual a abrangência e duração desses projetos? }\end{array}$ & - Determinação da Trajetória \\
\hline $\begin{array}{l}\text { Realizou algum treinamento técnico para participar dos } \\
\text { projetos? } \\
\text { O treinamento foi realizado dentro ou fora da empresa? } \\
\text { Participou de grandes projetos da empresa? }\end{array}$ & $\begin{array}{l}\text { - Aquisição de Saber Externo (learning by training e } \\
\text { troca de experiências com especialistas externos) } \\
\text { - Aquisição de Saber Interno (learning by training) }\end{array}$ \\
\hline $\begin{array}{l}\text { As equipes dos projetos em que participou eram } \\
\text { formadas apenas por funcionários internos? } \\
\text { Houve participação de consultores e especialistas } \\
\text { externos e, em caso positivo, qual o papel dos } \\
\text { consultores ou especialistas externos no projeto? } \\
\text { Ocorreu a aprendizagem e aplicação de ferramentas de } \\
\text { gestão de projetos? }\end{array}$ & $\begin{array}{l}\text { - Determinação da Trajetória } \\
\text { - Aquisição de Saber Externo (troca de experiências } \\
\text { com especialistas externos, reuniões do projeto, } \\
\text { brainstorming) }\end{array}$ \\
\hline $\begin{array}{l}\text { Algum projeto em que participou foi desenvolvido } \\
\text { com apoio de faculdades, governo, fornecedores } \\
\text { subcontratados ou outras empresas? }\end{array}$ & $\begin{array}{l}\text { - Determinação da Trajetória } \\
\text { - Aquisição de Saber Externo (troca de experiências } \\
\text { com especialistas externos, reuniões do projeto, } \\
\text { brainstorming) }\end{array}$ \\
\hline $\begin{array}{l}\text { Quais os pontos positivos e as dificuldades encontradas } \\
\text { na realização de cada projeto? } \\
\text { O que pôde ser aprendido com os projetos de que } \\
\text { participou? O que foi aprendido e pôde ser aplicado em } \\
\text { projetos posteriores? }\end{array}$ & $\begin{array}{l}\text { - Determinação da Trajetória } \\
\text { - } 4 \text { características dos processos de aprendizagem } \\
\text { (variedade, interação, intensidade e funcionamento) }\end{array}$ \\
\hline $\begin{array}{l}\text { Já participou como multiplicador de conhecimentos } \\
\text { gerados com a realização do projeto? Em caso positivo, } \\
\text { qual a abrangência dessa atividade de multiplicação do } \\
\text { conhecimento? }\end{array}$ & $\begin{array}{l}\text { - Determinação da Trajetória } \\
\text { - Socialização do Conhecimento (Ministrou programas } \\
\text { de treinamento formais e on the job, baseados em } \\
\text { mecanismos de learning by doing e learning by } \\
\text { training) }\end{array}$ \\
\hline $\begin{array}{l}\text { O conhecimento gerado a partir dos projetos } \\
\text { desenvolvidos encontra-se na forma de normas, } \\
\text { procedimentos, documentos, registros ou instruções de } \\
\text { trabalho? } \\
\text { Quem participou da elaboração dessa documentação? } \\
\text { Como foram feitos os treinamentos aos funcionários no } \\
\text { que se refere a essa documentação? }\end{array}$ & $\begin{array}{l}\text { - Determinação da Trajetória } \\
\text { - Codificação do Saber (Padronização de métodos } \\
\text { para o desenvolvimento de atividades por meio } \\
\text { de documentos, procedimentos e registro; nível de } \\
\text { abrangência e acesso a esta base de conhecimentos } \\
\text { padronizados) }\end{array}$ \\
\hline $\begin{array}{l}\text { Os projetos de que participou utilizaram a base de } \\
\text { conhecimento gerada em projetos anteriores? } \\
\text { A definição desses projetos levou em conta a base } \\
\text { tecnológica desenvolvida com os projetos anteriormente } \\
\text { realizados? } \\
\text { Existem ferramentas institucionalizadas que permitem } \\
\text { um feedback em relação à eficácia e eficiência dos } \\
\text { projetos desenvolvidos? }\end{array}$ & $\begin{array}{l}\text { - Determinação da Trajetória } \\
\text { - Socialização (Programas de Treinamento para } \\
\text { preparação dos participantes para execução de } \\
\text { projetos, learning by system performance feedback) } \\
\text { - Codificação do Saber (Utilização de conhecimento } \\
\text { padronizado referente ao desenvolvimento de } \\
\text { atividades; nível de abrangência e acesso a essa base } \\
\text { de conhecimentos padronizados) } \\
\text { - Aspectos relacionados aos paradigmas tecnológicos }\end{array}$ \\
\hline
\end{tabular}


Apêndice 1. Continuação...

\begin{tabular}{|c|c|}
\hline Questões & Objetivo \\
\hline $\begin{array}{l}\text { Já participou de algumas visitas técnicas em outras } \\
\text { empresas do mesmo segmento? Já realizou visitas em } \\
\text { outras empresas com o objetivo de Benchmarking? } \\
\text { Já recebeu visitas de outras empresas com objetivo de } \\
\text { Benchmarking? }\end{array}$ & $\begin{array}{l}\text { - Determinação da Trajetória } \\
\text { - Aquisição de Saber Externo (troca de experiências } \\
\text { com especialistas externos, reuniões do projeto, } \\
\text { brainstorming) } \\
\text { - } 4 \text { características dos processos de aprendizagem } \\
\text { (variedade, interação, intensidade e funcionamento) }\end{array}$ \\
\hline $\begin{array}{l}\text { As atividades que já realizou e que desempenha } \\
\text { atualmente dependem de auxílio técnico de profissionais } \\
\text { externos? } \\
\text { A empresa possui sistema de gestão ISO } 9000 \\
\text { ou referente a outras certificações? Quando foi } \\
\text { implementado? } \\
\text { Você participou do projeto de implantação desse sistema } \\
\text { de gestão? }\end{array}$ & $\begin{array}{l}\text { - Determinação da Trajetória } 4 \text { características dos } \\
\text { processos de aprendizagem (variedade, interação, } \\
\text { intensidade e funcionamento) }\end{array}$ \\
\hline $\begin{array}{l}\text { Em sua área de atuação, participa de atividades junto a } \\
\text { equipes multidisciplinares? } \\
\text { Qual a frequência de reunião desse grupo? } \\
\text { O trabalho em equipe contribuiu para troca de } \\
\text { experiências? } \\
\text { A participação em grupos de trabalho contribuiu para } \\
\text { multiplicação de conhecimentos adquiridos por meio de } \\
\text { treinamentos? } \\
\text { A experiência com atividades desenvolvidas em } \\
\text { grupos de trabalho multidisciplinares possibilitou sua } \\
\text { contribuição com sugestões de melhoria em atividades e } \\
\text { projetos? }\end{array}$ & $\begin{array}{l}\text { - } 4 \text { características dos processos de aprendizagem } \\
\text { (variedade, funcionamento, intensidade e interação) }\end{array}$ \\
\hline $\begin{array}{l}\text { Participa ou já participou de atividades relacionadas a } \\
\text { job rotation, treinamentos on the job? } \\
\text { Existe uma frequência definida de realização destas } \\
\text { iniciativas ou são feitas de forma pontual? } \\
\text { A organização dessas iniciativas segue programações } \\
\text { estabelecidas para treinamentos oferecidos pela } \\
\text { empresa? }\end{array}$ & $\begin{array}{l}\text { - } 4 \text { características dos processos de aprendizagem } \\
\text { (variedade, funcionamento, intensidade e interação) }\end{array}$ \\
\hline
\end{tabular}

